\title{
Analysis on the Impact for Power Quality of Wind Farms and Network Operation
}

\author{
Baozhong Gan \\ Jinzhou Power Supply Branch \\ State Grid Liaoning Electric Power Supply Co. Ltd \\ Jinzhou, China \\ ganbzjz@163.com
}

\author{
Tao Liu \\ Jinzhou Power Supply Branch \\ State Grid Liaoning Electric Power Supply Co. Ltd \\ Jinzhou, China \\ liutjz@163.com
}

\begin{abstract}
After entering the twentieth century, environmental pollution and energy crisis is getting worse, the development and utilization of new energy sources in the future had already become an important measure of China's energy use and development. Wind power as a new form of electrical energy directly affect our supply of electricity. Due to intermittent and random wind, the wind farm grid power system will have an impact. As wind farms have been expanding their access to grid capacity has been increasing, and the stable operation of the power grid caused some impact. Is to work characteristics of wind power as a starting point, the impact of wind farms on the current network operation and quality of the power supply to start discussion and proposed improvement measures to enhance its power level to meet electricity demand.
\end{abstract}

Keywords- environmental; energy; development; electricity; wind farms (key words)

\section{INTRODUCTION}

The principle of wind power generation is the use of wind driven windmill blades rotate, then the rotational speed boost through the growth machine to encourage generators. According to the current windmill technology, which is about three meters per second wind speed (degree breeze), we can begin to generate electricity[1].

Wind power is very popular in Finland, Denmark and other countries; China is also a strong proponent of the western region. Small wind power system efficiency is high, but it is not only composed by a generator head, but a certain tech small systems: wind generators charger digital inverter. Generator head, swivel, tail blade components. Each part is very important function of each part: leaf is used and accepted by the nose into the wind energy; tail blade always to the wind direction for maximum wind; swivel head allows the flexibility to rotate in order to achieve function to adjust the direction of the tail; the head is a permanent magnet rotor, stator winding cutting magnetic field lines generated electricity.

Frequency of the system and the system's real power is closely linked, to some extent, in terms of real power system determines the frequency of the system. Mainly because the driving force behind the wind farm is wind, wind itself has intermittent and random, intermittent, and precisely because of this randomness, making wind turbines for electricity will change over time as well as the size of the wind changes constantly change. Because of this intermittent wind and randomness, making the wind has not controllable, if you want to wind through the current control technology is clearly undesirable. Wind strength can not be controlled, directly affect the ability of the system as well as FM wind farm capacity. Wind farm power system if the change is too large, not only can affect the quality of electricity, they can even cause the collapse of the power system directly[2]. Therefore, in the actual wind farm management process, as well as the relevant authorities need to set some fast FM unit, so you can ensure that the intensity of the wind farm capacity, FM, so do the balance of power in the power system. However, it should be noted that, because of the complexity of China's electric power system consisting of power, making rapid frequency modulation unit either too costly or crew shortages, these issues also need to support not only need funding technology. Therefore, how to reduce the impact of wind farms and network voltage stability is an important direction for future research in the electric field.

In the actual process of wind farm operations, and gridconnected wind farms for power system directly affects not only reflected in the impact on the grid, but also reflect the impact of voltage and frequency stability in. If largescale wind farm, then the stability of the voltage on the larger, smaller-scale power plants, then the stability of the voltage is also smaller. In general, the stability of largescale power plants include not only the voltage of the voltage flicker and wave abnormalities, but also include the impact of voltage fluctuations. In the actual process of wind farm operations, reactive power is a direct impact on voltage stability critical factor. Wind farms by absorbing reactive power grid to form reactive load has some damaging effects. But the wind farm for the damaging effects of reactive load is absorbed by the role and impact of wind farms in the wind, mainly due to intermittent wind energy and has a certain randomness, and as such, resulting in a direct impact on the wind farm to the grid Stability of voltage and frequency. In addition, the reactive power compensation equipment operating efficiency and voltage is proportional to the relationship, if turbine voltage drop, it will directly lead to reduced turbine 
reactive power compensation amount, which in turn lead to a further decline in voltage levels. Conversely, if the wind speed electric fan fails or falls, the wind farm voltage will appear on the rise[3].

\section{WIND FARMS OPERATING CHARACTERISTICS}

A wind power generation basic process schematic is shown in Fig .1, when wind enters the wind turbine will drive hub rotating turbine wheel, thereby converting wind energy into mechanical energy, and the hub in the mechanical transmission mechanism, such as an auxiliary gear at the rotor mechanical be conveyed to a generator rotor, drive the rotor, so that the generator is running power, electricity substation last action in the area of the output of the wind farm to the grid for users to use.

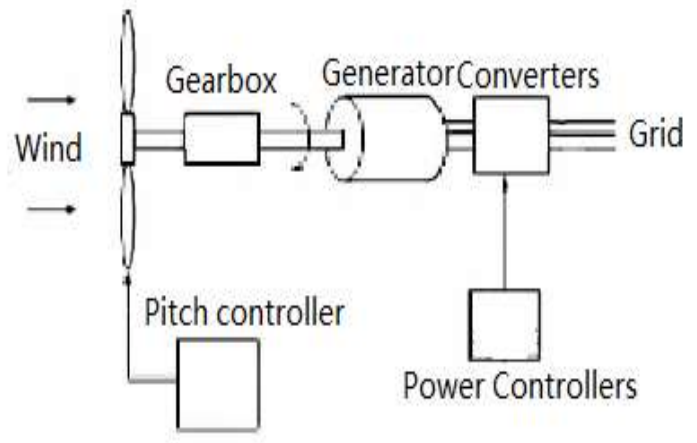

Figure 1. Wind power generation basic process schematic

From the above, wind power wind energy as the driving force, while achieving full utilization of the resources of nature also has the advantage of a basic zero emissions, in addition to its small footprint, the construction time is short, and therefore the economy and environmental protection are more impressive[4]. However, due to their nature, wind speed, wind direction can not be artificially controlled, and thus will result in the presence of wind farm power output volatility, after the grid will make the power grid unstable.

\section{THE IMPACT OF WIND FARMS ON THE GRID NETWORK OPERATION}

Due to the distribution of wind energy, wind speed, power grid system layout and other factors, the power output of the wind farm and the presence of intermittent volatility, in its capacity is small, the impact of this change on the grid can be ignored, but if the wind field generating capacity is large, accounting for a high proportion of grid power, the impact of such an unstable power output of the power supply quality will not be ignored, which is mainly reflected in the cause voltage fluctuations and flicker, grid frequency and grid impact impact of the short-circuit current and power flow and power plants affect other devices.

\section{A. Flicker and voltage fluctuations}

Cause power flicker and voltage fluctuations due to instability after major wind farm output power grid, and a schematic diagram of wind turbines and wind farms in the network is shown in Fig .2 and wind farms in the network.
If the grid voltage Ugrid remains constant, but the wind turbine output power by the time the effects of changing wind speed, etc., will result in terminal voltage Uwind and and outlets voltage Upcc fluctuations, which led to the grid voltage changes, when the wind turbine when the output power fluctuations, this flash change is obvious.

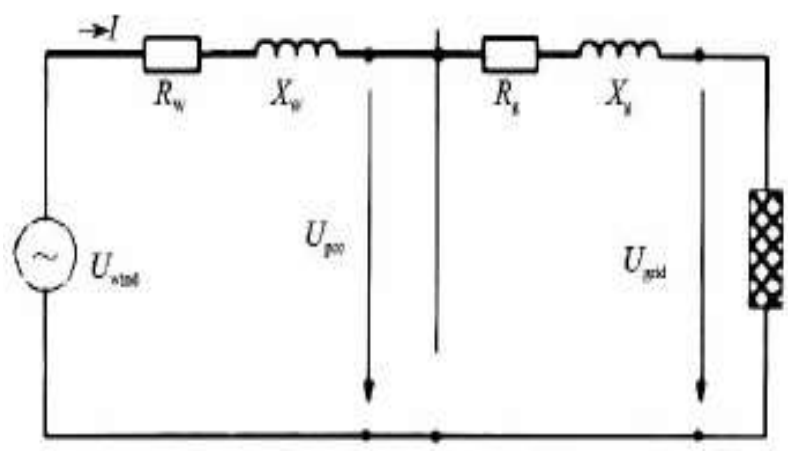

Figure 2. Schematic diagram of wind turbines and wind farms in the network

Judging from the actual operation of the grid system voltage fluctuations caused by wind farms and network operation mostly occur in some weak grid system. Due to the construction of a wind farm at the end of the multi-grid system, simple structure, small short-circuit capacity, so that when the wind speed, power lines, control systems and other changes, will cause significant changes in the wind turbine output power and causing the grid voltage instability, volatility, etc., affect the quality of power supply[5].

\section{B. Impact on the grid frequency}

With the expansion of wind power in the grid, the power delivered to the grid which is also increasing, thereby affecting the result of fluctuations in power output while the grid frequency is also caused more prominent. If the grid system is disturbed, it will cause the grid voltage is reduced, and may lead to poor performance of low pressure through the wind turbine downtime. Thus, after the wind farm grid, the grid other conventional type of units to be in the frequency response of a better performance, with the ability to track the timely remedy regulate grid frequency fluctuations; In addition, taking into account fluctuations in wind power to run the transmission changes randomly in no wind or wind speed smaller state, the frequency of the grid will be drastically reduced, thus a serious threat to the stability of the grid frequency, in this case should increase the reserve capacity of the grid system and select the optimal scheduling operation mode.

\section{Impact effect on the grid}

More use of wind farms in the induction motor as a power generation mechanism when grid power is consistent with the phase sequence while the speed close to the synchronous speed of conditions to be met in order to smooth the grid. However, due to the lack of independence of the asynchronous motor excitation structure, before the grid voltage to zero, and thus after the network reaches a stable voltage required to go through a transition, in the process of formation of the rated current value is greater than 5-8 times the impact of 
current, after several hundreds of milliseconds or seconds after steady trend. The impact of current at the time of the formation of the grid with the grid voltage, change slip of induction motors and their transient reactance and network processes and change. If the wind farm is in the capacity of the larger grid power system, due to the impact of the current impact of the grid due to be ignored, but if the impact of current parallel in a small grid, then grid formed will make the grid voltage dips and may pose a threat to the safe use of line with other devices[6].

Now, in the actual construction of the wind farm is the most used asynchronous generators, asynchronous generator and synchronous generator is different, it has no independent excitation device, so in order to establish a magnetic field, it is necessary to draw from the grid. The officer if the wind turbine to the grid, it will directly generate current, this current is a kind of surge current, this will change with the impact of current wind farm capacity varies, if the wind farm capacity is too large, then the current impact will directly affect the normal operation of the power grid, if the electric field capacity is too small, will not affect the normal operation of the grid. Of course, has a great impact on the current associated with the grid voltage asynchronous generator, slip and transient reactance, etc., if the proportion of wind power capacity in the power system occupies too large, instantaneous power down, it will directly affect the asynchronous generator machine grid smoothly. Asynchronous generator start, you need to draw a lot of power from the grid, draw a lot of power grid after the general to produce than the rated current to nearly seven times the current, which will directly affect the high-current power other devices smoothly. If serious, it will directly affect the stability of the grid. With the investment of reactive compensation devices, power will be restored to a certain extent, but will cause the motor off the network, thus making the grid voltage upward trend.

\section{Impact on the short-circuit current and power flow}

Asynchronous motors used in the wind farm will be conveyed during operation under its own electromotive force to short-circuit the short circuit current, and thus to increase the short-circuit current value of the grid system, and thus minimize the effect of the wind farm to the grid when a short circuit current [7]. In addition, the impact of parallel operation of wind turbines for power flow can not be ignored, wind speed, the motor running and other factors may cause the wind turbines off the network, which could cause power flow changes or transfer; in addition, if the wind turbine Low penetration itself does not have the performance, in the event of a fault transient voltage fluctuations may also cause off-grid, affect the stability of operation of the grid.

\section{E. Impact on power quality}

Includes not only the quality of electric power quality waveform, frequency, voltage quality but also the quality, wind farm grid for Quality of electricity mainly from energy related to these three factors, here we come to the waveform quality, for example, analysis at wind farm grid impact waveform quality. Overall, for the waveform quality and the impact of the wind farm network mainly in the following two aspects: first, the actual process of wind farm operators, wind farms, the management will use the soft-start approach to control of the wind farm, The aim must be to further reduce the wind farm to the power system shock. However, precisely because of the use of such soft-start approach, coupled with soft start is included with other power electronic devices, making the wind farm power equipment appear harmonics, affect the stability of the power system. Second, in the actual process of wind farms and network operation, the relevant personnel for wind farms and network operation mode $\mathrm{AC}$ and DC transformed means of communication, in this conversion process, the inverter plays a key The role of the inverter in the actual operation of the process will produce a lot of harmonics, or even absorb reactive power to a certain extent, and thus directly affect the normal operation of the wind farm.

\section{IMPROVEMENTS AND NETWORK OPERATION OF THE WIND FARM IMPACT ON THE GRID}

With the development of technology, the wind farm to keep the intelligent direction of the development of largescale, but its impact on power quality is still there. To better improve the efficiency of wind turbines, and to improve the quality of its output power, may be appropriate to apply the following measures in the wind farm grid runtime:

\section{A . Reactive power compensation techniques to improve wind farm}

The induction generator wind farms are mostly inductive element during operation needed reactive support, reactive compensation amount of how much voltage associated with the access point. In the wind farm can be applied to dynamic reactive power compensation device (SVC) and SMES. The former can be adjusted according to local conditions reactive compensation required for grid power value, thus reasonable voltage regulation size and improve system performance. SVC in the wind farm should be installed in the exit, by calculating the amount of voltage deviation of wind farms in the access point to control the amount of reactive power compensation to stabilize the wind farm node voltage, reduce grid power fluctuations caused instability; the SMES system with SMES the active and reactive power for comprehensive regulation of performance, power compensation system can be flexibly adjusted to reduce the volatility of the output power of the wind farm, maintain the stability of the grid voltage[8].

\section{B. Use HVDC grid-connected in wind farms}

HVDC Light technology is mainly based on the PWM voltage source converter (VSC) technology, thyristors, and thus have a direct current transmission performance. Application of the technology in the wind farm can be an effective solution to access due to the dispersion caused by the power transmission corridor problem, but because of the reactive power compensation with automatic adjustment of control, can be overcome using HVDC circuit capacity of the wind farm capacity is limited to further ensure the stability of the power grid, and to 
guarantee delivery to the grid power qualityCommon treatment failure protection.

\section{$C$. Improve the accuracy of prediction of wind farm power generation}

Wind farms operating efficiency depends mainly on wind speed, with the continuous breakthroughs in neural networks and other new technologies, should improve the ability to predict the wind speed, and thus contribute to more accurately estimate the performance of wind power, making the grid more flexible to accommodate wind farms; in addition, the control performance to be optimized to deal with wind farms, so that the general performance of the generator to work closer, in order to rationalize the scheduling of work to ensure the safe operation of the grid system[9].

Wind power itself undoubtedly has a good ecological benefits, belong to clean energy, environmentally friendly. However, in accordance with the foregoing analysis, because wind power feed-in, will definitely lead to lower other operating economy of power plants, thermal power plants which bear the brunt. Remove frequent starts and stops caused by high costs, fuel consumption of thermal power plants, coal consumption will increase, and the life of the unit due to start and stop frequently reduced[10]. Therefore, comprehensive view, in accordance with the current level of technology, the overall impact of wind power on the environment is still open to question.

\section{CONCLUSION}

In summary, with the growing size of the wind farm, the impact of wind power this unstable dispersion characteristics of the power grid even more remarkable. You can adopt effective measures to improve the operating performance of wind farms, to reduce the impact of wind power on the grid. Depth study of the impact of wind farms and power system network, and explore strategies to improve power system stability, the future stability of the departments concerned in terms of the power system is an important topic and objectives. Wind energy is the driving force of wind power, which itself has a randomness and intermittent driving force behind it with other conventional power plants have very different wind turbine has many characteristics different from the traditional generator set, after which the grid is bound to affect the grid normal operation.

\section{ACKNOWLEDGMENT}

The authors gratefully acknowledge the contribution of co-workers and reviewers' comments.

\section{REFERENCES}

[1] LZ Zhang and X.Hu, "Research on the safe operation of the wind turbine," Wind, vol.18,pp.92-95, July 2013

[2] H.F.Yue, "Safety management of wind farms," Scie. Tech.Info, vol. 12,pp.23-27, May 2011

[3] Y.N.Guo.,"On the wind power production safety standardization management measures," Power \& Energy, vol.7,pp.17-21, July 2012

[4] X.Q.Wu, "Reliability and protection of Dynamic Performance Simulation," Pow.Sys.Eng, vol.5,pp.34-39, April 2012

[5] Y.Y.Cheng and W.L.Li, "Wind turbines and affect the operation of the power grid network," For electricity, vol.2,pp.12-16, June 2012

[6] H.B.Bai and R.H.Wang. "the net impact on power quality analysis of wind farms," Auto.Elec.Po.Sys,vol.12,pp.34-38, May 2012

[7] K.Xu, C.Wu and X.J.Yang"Wind Power Structure Analysis and Control VSC-HVDC system," Pow.Sys.Tech,vol.33,pp.103-108, May 2009

[8] Q.Wang and X.H.Chen, "Large wind turbines and power systems and related networking issues," Modern electricity, vol.5,pp.34-38, May 2009

[9] Y.P.Feng, "Substation operation Problems and Countermeasures," Chi.New.Tec. New. Produ, vol.24, pp.4-8, April 2011

[10] X.Y.Li and Z.Yu, " Offshore wind Progress," Solar Technology, vol.25, pp.78-84, April 2012 